\title{
Aerosol prevention box for regional anaesthesia for eye surgery in COVID times
}

\author{
V. V. Jaichandran ${ }^{1} \cdot$ Rajiv Raman ${ }^{2}$
}

Received: 19 May 2020 / Revised: 4 June 2020 / Accepted: 4 June 2020 / Published online: 16 June 2020

(c) The Author(s), under exclusive licence to The Royal College of Ophthalmologists 2020

General anaesthesia (GA) with airway intervention leads to aerosol generation, which exposes the healthcare team to risk of transmission of COVID-19 both during intubation and extubation. The odds of transmission of respiratory infection during tracheal intubation to a healthcare professional is 6.6 times compared with those who are not exposed to tracheal intubation [1]. Recently there have been few innovations, of using an aerosol box to prevent aerosol transmission during GA [2,3]. However, its use has not been described in regional anaesthesia (RA).

Both American Society of Regional Anesthesia and Pain Medicine and European Society of Regional Anesthesia and Pain Therapy recommend RA to be preferred over GA for patients with COVID-19 to reduce the risk of transmission [4]. All India ophthalmology society recommends that, in the current COVID-19 scenario most of the eye surgeries should be performed under RA. For administering regional eye blocks, it is recommended to wear surgical gown, double gloves, N95 masks with or without face shield while the patient is allowed to wear a surgical mask [5].

There are evidences that needle blocks per se or needle blocks associated with intravenous sedation may result in sneezing owing to direct trigeminal nerve stimulation [6]. The incidence of this photic sneeze reflex is reported in approximately $24 \%$ of the population [7]. This would result in risk of aerosol transmission to the healthcare provider. Also, in patients with chronic bronchitis and those with history of hyperactive airways there is a high

V. V. Jaichandran

drvvj@snmail.org

1 Department of Anaesthesiology, Medical Research Foundation, Sankara Nethralaya, 41/18, College Road, Nungambakkam, Chennai, Tamil Nadu, India

2 Shri Bhagwan Mahavir Vitreoretinal Services, Medical Research Foundation, Sankara Nethralaya, 41/18, College Road, Nungambakkam, Chennai, Tamil Nadu, India chance for cough to occur during regional block and even thereafter. Hence, during administration of regional blocks, if the patient accidentally coughs or sneezes then there is risk of exposure to the aerosols. To prevent such risk of exposure to aerosol, the authors describe a new technique for performing peribulbar block in the current COVID situation.

Aerosol box can be used to perform needle blocks for eye surgery. The box is a rectangular box made up of transparent acrylic sheet (5 mm thickness). The dimensions of the box are 15 inches length, 21 inches breadth and 19 inches height. The size of holes ( 2 on the sides and 2 on the head end) was 5 inch diameter. Front of the box has a transparent thick plastic sheet.

Local anaesthetic solution loaded and labelled in 10cc syringe, 23G 1 inch needle and 26G $1 \frac{1}{2}$ inch needle, cotton soaked in $1 \%$ cetrimide solution and an sterile gauze are all kept in a plastic tray alongside the patient head. Another empty cup should be kept by the side, to discard the above things after their use. To allay any anxiety, patient should be informed that this box acts as extra barrier to prevent any risk of aerosol transmission either from him/her to the healthcare worker or vice versa too.

The aerosol prevention box is kept around the patient's head. Standing by the side of the operating table, one hand is passed through the front side of the box, while the other hand is passed through the side hole of the box as shown in the image (Fig. 1a). Routine aseptic cleaning with the cotton soaked in cetrimide solution is done and the cotton is discarded in the other cup. Using 23G needle, inferolateral injection is performed, following which sterile gauze is kept over the eye and digital massage is carried out (Fig. 1a). Thereafter, the efficacy of the block should be assessed. If akinesia is not obtained fully, then the supplementary injection is performed by standing at the head end of the table. Both hands are passed through the two holes provided at the head end of the aerosol box (Fig. 1b). The medial peribulbar injection is performed using $26 \mathrm{G}$ needle, following which digital massage is 
Fig. 1 The aerosol prevention box used during regional blocks. a Administration of inferolateral peribulbar injection. b Administration of medial peribulbar injection.
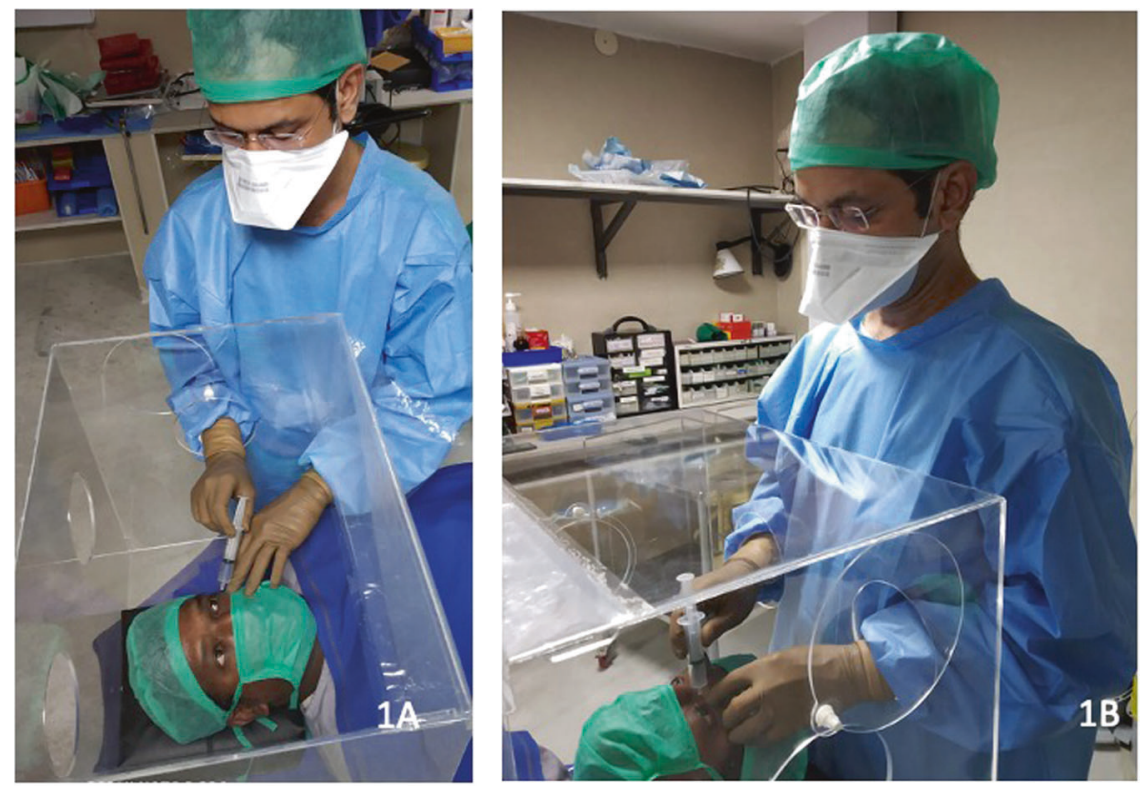

carried out once again. The needles and syringe are discarded in the cup. After the procedure is over, the aerosol box is cleaned by $70 \%$ isopropyl alcohol and dried before using it on the next patient. At the end of the day, it can be cleaned by $1 \%$ hypochlorite solution and $70 \%$ isopropyl alcohol.

We describe a novel barrier device for potentially reducing aerosol and droplet transmission to healthcare workers during the administration of regional anaesthesia for ophthalmic surgeries in COVID-19 patients.

Acknowledgements Department of Maintenance, Sankara Nethralaya, Chennai, India.

\section{Compliance with ethical standards}

Conflict of interest The authors declare that they have no conflict of interest.

Publisher's note Springer Nature remains neutral with regard to jurisdictional claims in published maps and institutional affiliations.

\section{References}

1. Tran K, Cimon K, Severn M, Pessoa-Silva CL, Conly J. Aerosol generating procedures and risk of transmission of acute respiratory infections to healthcare workers: a systematic review. PLOS ONE. 2012;7:e35797.

2. Brown S, Patrao F, Verma S, Lean A, Flack S, Polaner D. Barrier system for airway management of COVID-19 patients. Anesth Analg. 2020. https://doi.org/10.1213/ANE.0000000000004876.

3. Lai Y, Chang C. A carton-made protective shield for suspicious/confirmed COVID-19 intubation and extubation during surgery. Anesth Analg. 2020. https://doi.org/10.1213/ANE.0000000000004869.

4. Uppal V, Sondekoppam RV, Lobo CA, Kolli S, Kalagara HKP. Practice recommendations on neuraxial anesthesia and peripheral blocks during the COVID-19 pandemic. http://www.asra.com/ covid-19/raguidance.

5. Sengupta S, Honavar SG, Sachdev MS, Sharma N, Kumar A, Ram J, et al. All India Ophthalmological Society-Indian Journal of Ophthalmology consensus statement on preferred practices during the COVID-19 pandemic. Indian J Ophthalmol. 2020;68:711-24.

6. Tao JP. Sneezing reflex associated with intravenous sedation and periocular anesthetic injection. Am J Ophthalmol. 2009;147:183.

7. Abramson DC. Sudden unexpected sneezing during the insertion of peribulbar block under propofol sedation. Can J Anaesth. $1995 ; 42: 740-3$ 